\title{
Technical note \\ Infrastructure for irrigation of grapevines with diluted winery wastewater in a field experiment
}

\author{
PA Myburgh'*, EL Lategan' and CL Howell' \\ 'Infruitec-Nietvoorbij Institute of the Agricultural Research Council, Private Bag X5026, Stellenbosch, 7599
}

\begin{abstract}
Winemaking produces large volumes of poor quality water. The possibility to re-use this water for vineyard irrigation was investigated in a field trial. For this purpose, winery wastewater had to be diluted to chemical oxygen demand (COD) levels ranging between 100 and $3000 \mathrm{mg} / \ell$. The relatively simple infrastructure and procedure required to dilute the winery wastewater in $15 \mathrm{~m}^{3}$ tanks are described. Analyses of the diluted winery wastewater confirmed that the COD concentrations were reasonably close to the target values. Furthermore, measuring COD concentrations in the irrigation water while it was being pumped from the tanks confirmed that the concentrations of diluted wastewater within the tanks were fairly homogeneous, and that effective mixing had taken place while tanks were being filled. The COD measurements were more reliable when the oxidation time was standardised at $2 \mathrm{~h}$ compared to shorter periods, irrespective of the level of COD in the water. After initial practical problems and sources of error were eliminated, the accuracy of treatment application obtained in terms of the target COD concentrations was acceptable.
\end{abstract}

Keywords: chemical oxygen demand, winery wastewater, re-use, irrigation, grapevines

\section{INTRODUCTION}

Wineries produce large volumes of wastewater, particularly during the harvest period from February until March. Generally, the chemical oxygen demand (COD) in the wastewater (Arienzo et al., 2009; Mulidzi et al., 2009a; Conradie et al., 2014) is higher than the allowable limits for irrigation of agricultural crops as stipulated by the General Authorisation for legislated limits for irrigation with wastewater in South Africa (DWA, 2013) (Table 1). Surveys have shown that soil chemical conditions deteriorated where grazing paddocks were irrigated with winery wastewater over a period of time (Mulidzi et al., 2009b). Furthermore, the sodium (Na) in the water could accumulate in the soil, which could have negative effects on the soil physical properties in the long run (Arienzo et al., 2009; Laurenson et al., 2012). This could be more pronounced in dry regions where winter rainfall is inadequate to leach accumulated salts from the soil. An alternative to the grazing paddocks would be to re-use diluted winery wastewater for irrigation of agricultural crops. Since many wineries are close to, or even surrounded by, vineyards, it would be a logical alternative to re-use the diluted wastewater to irrigate grapevines. To assess the effects of diluted wastewater on grapevine growth, yield and wine quality, a research project was initiated and funded by the Water Research Commission (WRC). The project was co-funded by Winetech and the Agricultural Research Council (ARC). The Infruitec-Nietvoorbij institute of the ARC at Stellenbosch was contracted to carry out the field experiment.

The grapevines had to be subjected to irrigation with winery wastewater containing a range of COD levels to determine a possible threshold concentration for sustainable use. Control grapevines were irrigated with river water (raw water). Since

\footnotetext{
* To whom all correspondence should be addressed.

e-mail: myburghp@arc.agric.za

Received: 10 October 2014; accepted in revised form 25 August 2015
}

one of the major objectives was to assess the effect of the wastewater irrigation on wine quality characteristics, the experiment plots had to be large enough to produce at least $40 \mathrm{~kg}$ of grapes, i.e., the minimum required for small-scale winemaking. Furthermore, the water had to be applied with micro-sprinklers rather than drip to (i) distribute the water over the total surface and (ii) reduce the risk of emitter clogging. Therefore, relatively large volumes of water were required to apply a single irrigation for the 3 replication plots of each treatment. Consequently, the wastewater had to be diluted in large containers. Since previous wastewater studies were carried out in laboratories (Laurenson et al., 2012), there were no guidelines for diluting winery wastewater on such a large scale.

The objective of the study was to evaluate the efficiency of the dilution procedure where grapevines were subjected to irrigation with winery wastewater containing different levels of COD.

\section{MATERIALS AND METHODS}

\section{Experimental vineyard and layout}

The field trial was carried out in an 8-year-old commercial Cabernet Sauvignon/99 Richter vineyard near Rawsonville in the Breede River grape-growing region of the Western Cape, at $33^{\circ} 41^{\prime} \mathrm{S}$ latitude. The region has a Mediterranean climate and, based on the growing degree days from September until March (Winkler, 1962), the specific locality is in a Class V climatic region (Le Roux, 1974). The vineyard is located on an alluvial floodplain of the Du Toit's Kloof Mountains. The sandy soil belongs to the Longlands form (Soil Classification Working Group, 1991). The soil was deep delved to $1.0 \mathrm{~m}$ before planting. Grapevines were planted $2.4 \mathrm{~m} \times 1.2 \mathrm{~m}$ and trained onto a 4-strand lengthened Perold trellis (Booysen et al., 1992). During a WRC workshop on 15 May 2008 in Stellenbosch, the terms of reference for the project, including the 8 COD levels to which the winery wastewater had to be diluted, were finalised (Table 2). All treatments were 
TABLE 1

General Authorisation for legislated limits for chemical oxygen demand (COD), faecal coliforms, pH, electrical conductivity (EC) and sodium adsorption ratio (SAR) for irrigation with wastewater in South Africa (DWA, 2013)

\begin{tabular}{|c|c|c|c|}
\hline \multirow[t]{2}{*}{ Parameter } & \multicolumn{3}{|c|}{ Maximum irrigation volume allowed ( $m^{3} /$ day) } \\
\hline & $<\mathbf{5 0}$ & $<500$ & $<2000$ \\
\hline $\mathrm{COD}(\mathrm{mg} / \ell)$ & 5000 & 400 & 75 \\
\hline Faecal coliforms (per $100 \mathrm{~m} \ell$ ) & 1000000 & 100000 & 1000 \\
\hline $\mathrm{pH}$ & $6-9$ & $6-9$ & $5.5-9.5$ \\
\hline $\mathrm{EC}(\mathrm{mS} / \mathrm{m})$ & 200 & 200 & $70-150$ \\
\hline SAR & $<5$ & $<5$ & Other criteria apply \\
\hline
\end{tabular}

\begin{tabular}{|c|c|c|c|c|c|c|c|c|}
\hline & Inge & vels & the $n$ & $\begin{array}{l}\text { ABLE } \\
\text { stewa }\end{array}$ & dilute & diffe & tmen & \\
\hline Control & & & get $C$ & in dilt & ery w & $\mathrm{er}(\mathrm{mg}$ & & \\
\hline $\mathrm{T} 1$ & $\mathrm{~T} 2$ & $\mathrm{~T} 3$ & $\mathrm{~T} 4$ & T5 & T6 & T7 & T8 & T9 \\
\hline River water* & 100 & 250 & 500 & 1000 & 1500 & 2000 & 2500 & 3000 \\
\hline
\end{tabular}

${ }^{*}$ Abstracted from the Holsloot River

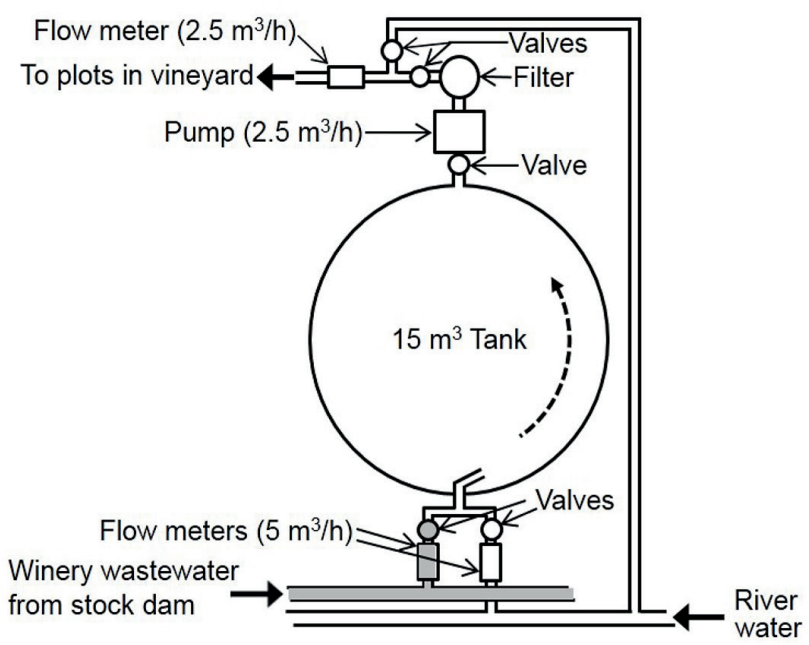

Figure 1

Diagram to illustrate the components used to dilute the winery wastewater in the tanks

replicated 3 times in a randomised block design. The experimental plots and grapevines were marked in July 2009.

Experimental plots comprised 2 rows of 6 grapevines each, with 2 buffer grapevines at each end and a buffer row on each side. Each experimental plot covered $104 \mathrm{~m}^{2}$.

\section{Installation and commissioning of the infrastructure}

The micro-sprinkler irrigation system, which allowed irrigation of the individual treatments, was installed in the vineyard during August 2009. To prevent possible damage to grapevine shoots during installation of the irrigation system, it was essential to complete this task before bud break in September. The micro-sprinklers (White base/white swivel, Gyro Sprinklers, Brackenfell) had a $30 \mathrm{l} / \mathrm{h}$ flow rate at $100 \mathrm{kPa}$. The $400-\mathrm{m}$ long, 110-mm diameter PVC pipeline required to convey the water from the wastewater pit at the winery to the experimental vineyard was also installed in August 2009. The COD levels in winery wastewater can vary considerably as the winery activities change over the course of a day. Therefore, the wastewater was first collected in a $20 \mathrm{~m}^{3}$ stock dam to obtain water with a stable concentration. The wastewater was pumped from the stock dam using a $30 \mathrm{~m}^{3} / \mathrm{h}$ pump to the 8 plastic tanks, one for each dilution treatment, at the mix and distribution facility near the vineyard. The distribution system design allowed irrigation with diluted wastewater from the tanks, as well as direct irrigation with river water (Fig. 1). It was estimated that the vineyard would require $35 \mathrm{~mm}$ irrigation every 14 days to allow approx. 50\% plant available water depletion between irrigations. Since it was decided to rinse the irrigation system with $2 \mathrm{~m}^{3}$ river water following each diluted winery wastewater irrigation, only $13.5 \mathrm{~m}^{3}$ diluted wastewater was required for the 3 replication plots of each treatment. Based on this, the wastewater was diluted in $15 \mathrm{~m}^{3}$ tanks, which allowed $1.5 \mathrm{~m}^{3}$ spare capacity to reduce the risk of wastewater spills. Construction of the wastewater mix and distribution facility commenced on 15 January 2010, and was completed on 9 February 2010. Commissioning of the water mix and distribution facility was completed on 12 February 2010.

The operational wastewater treatment, which was followed for this winery but may also be applicable to other wineries, is as follows: Wastewater coming from the winery is first screened to remove coarse particles. During this process, lime is added to increase the $\mathrm{pH}$ of the water. The wastewater then flows through a sedimentation pond to allow settling of substances, e.g., tartaric acid. The treated water is collected in a pit from where it is pumped onto a grass paddock.

The dilution or mixing procedure for the field trial was carried out according to the following steps: First, the stock dam was filled with wastewater from the collection pit at the winery. Following this, the COD in the stock dam water, as well as in the water from the Holsloot River, approx. $80 \mathrm{~m}$ from the tanks, was measured. The COD in the water samples was measured using a portable spectrophotometer (Aqualitic CODreactor, Dortmund) with the appropriate test kits (COD, CSB, $0-15000 \mathrm{mg} / \ell$ ). This procedure requires a 2 -h oxidation time. The COD levels were used to calculate the volumes of winery wastewater and water required to obtain the different target COD levels (Table 2). The volume $\left(\mathrm{m}^{3}\right)$ of wastewater required from the stock dam $\left(V_{s}\right)$ to obtain a certain target COD concentration $\left(\mathrm{COD}_{T}\right)$ was calculated as follows:

$$
V_{S}=\left(\mathrm{COD}_{T}-\mathrm{COD}_{R}\right) \times V_{T} /\left(\mathrm{COD}_{S}-\mathrm{COD}_{R}\right)
$$


where: $\mathrm{COD}_{R}$ and $\mathrm{COD}_{S}$ are the COD concentrations $(\mathrm{mg} / \ell)$ in the river water and the stock dam, respectively, and $V_{T}$ is the tank volume $\left(\mathrm{m}^{3}\right)$. Since the $\mathrm{COD}_{R}$ was undetectably low, a value of $1 \mathrm{mg} / \ell$ was used in the calculations. The required volume of winery wastewater for a specific treatment was first pumped into the designated tank. Following this, the tank was filled by pumping water from the river. Since the inlets were near the bottom of the tanks, the river water was forced to flow through the wastewater already inside the tanks. Furthermore, the inlet on the inside of the tank was set at an angle to create a swirling effect while water was flowing into the tank (Fig. 1). Once the tanks were filled, the water was pumped onto the treatment plots using $2.5 \mathrm{~m}^{3} / \mathrm{h}$ pumps (Fig. 1).

Approximately $1 \mathrm{~h}$ after the irrigation commenced, the COD in the diluted water was measured at the tank outflows. To avoid the settling of substances, the diluted water was never allowed to stand overnight in the tanks. Irrigations were applied almost immediately after the tanks were filled. Since the infrastructure was only completed during fruit ripening in the 2009/10 season, only 3 diluted winery wastewater irrigations were applied after the grapes were harvested. In the 2010/11, 2011/12 and 2012/13 seasons, 3 wastewater irrigations were applied before harvest, followed by 3 irrigations after harvest.
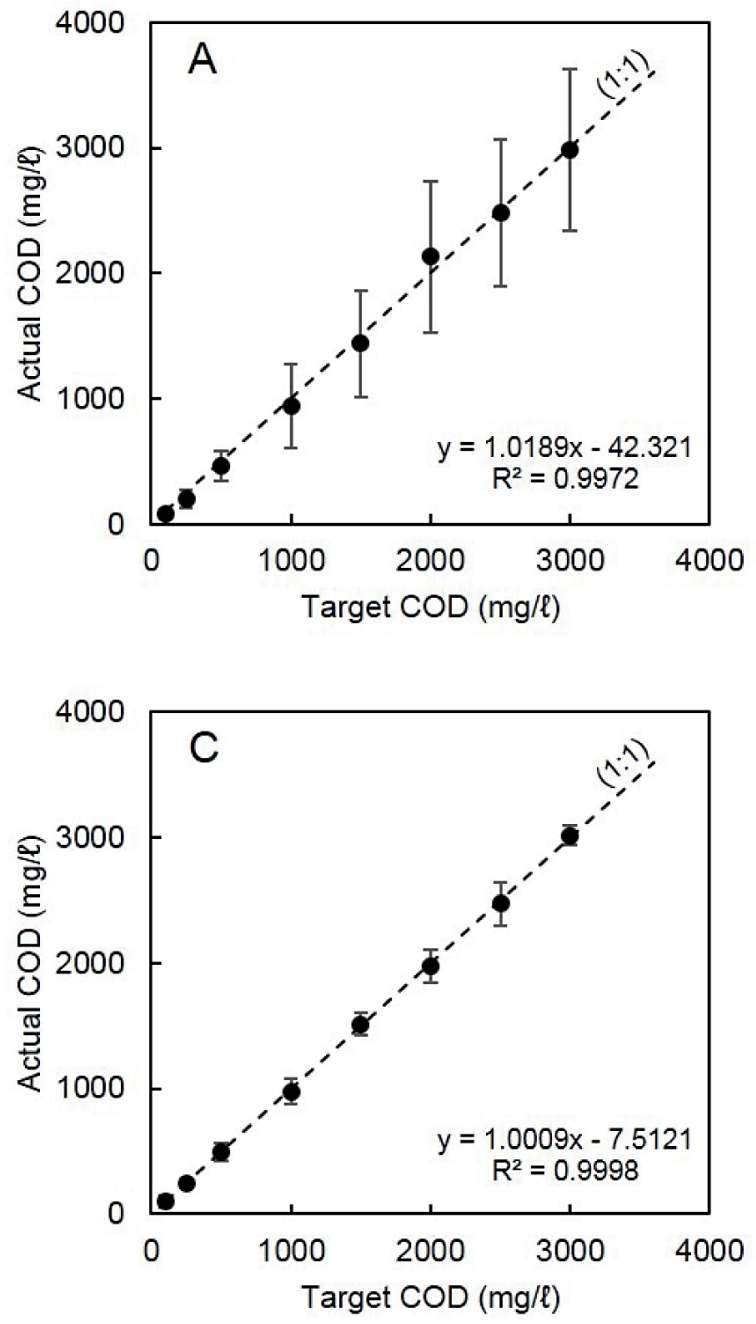

\section{RESULTS AND DISCUSSION}

\section{Efficacy of wastewater dilution}

The seasonal COD in the diluted winery wastewater was generally close to the treatment target values presented in Table 2 . However, in some cases the COD in the diluted water differed from the target treatment values. Therefore, the standard deviation from the mean was relatively large, particularly during the 2009/10 season (Fig. 2A). Possible reasons for the deviation from the target $\mathrm{COD}$ levels were as follows: The main pipeline was initially filled with river water after the system had been completed. The COD concentration in the water in the pipeline was not accounted for and, therefore, probably had a diluting effect when the water was mixed. From the second irrigation onwards, the main pipeline was filled with winery wastewater before the water was pumped into the tanks. The water meters used to monitor the volumes of water flowing into the tanks also presented problems, particularly when the flow rates increased when only 1 or 2 tanks were being filled at a time. This problem was overcome by marking the required water levels on the outside of the translucent tanks. An operator error also occurred when the plunger of the mechanical pipette was
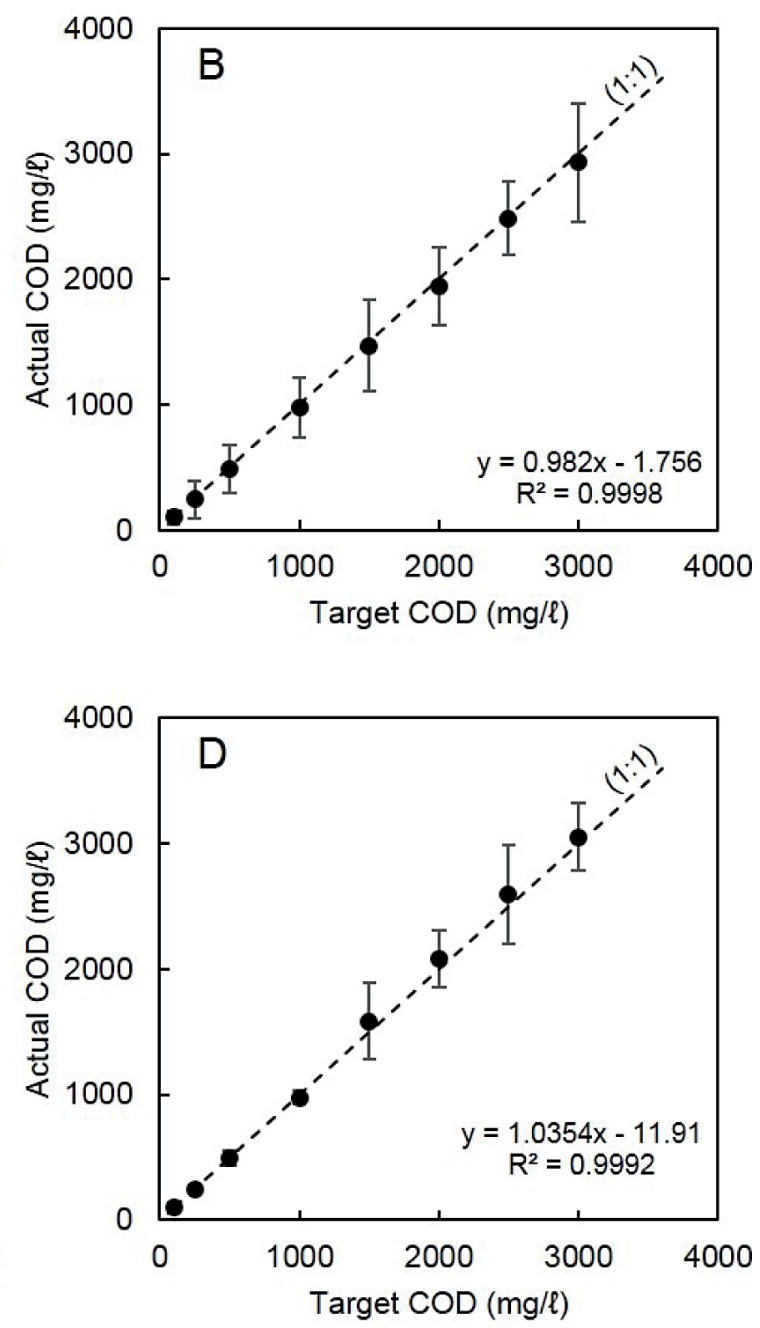

Figure 2

Relationship between mean actual chemical oxygen demand (COD) in diluted winery wastewater applied to grapevines and the target COD levels of treatments T2 to T9 in the (A) 2009/10, (B) 2010/11, (C) 2011/12 and (D) 2012/13 seasons. Vertical bars indicate standard deviation. 
pressed too deep when the water samples were transferred into the test kit vials for the spectrophotometric COD measurement. This caused an overestimation of the COD level in the stock dam, which in turn resulted in too low COD levels in the diluted water in the tanks, particularly when low COD in the winery wastewater required sample volumes of $2 \mathrm{~m} \ell$ compared to the $0.2 \mathrm{~m} \ell$ required for the higher COD levels, i.e. $>1500 \mathrm{mg} / \ell$.

Since the dilution and irrigation procedures took almost 3 days to complete, the project team investigated ways to save time. According to the technical advice from a supplier of COD test kits, 1-h oxidation time would be adequate for most COD levels in water samples. If the oxidation time could be reduced, it would significantly reduce the time required to carry out the whole procedure as described above, particularly the 2-h waiting period after the stock dam had been filled. Consequently, it was decided to reduce the oxidation time for the samples from the stock dam to $1 \mathrm{~h}$ for the second and third treatment applications in 2009. Since the actual COD levels after mixing were higher than the target levels in the second and third irrigations, the possibility that the $1 \mathrm{~h}$ oxidation time could have resulted in an underestimate of the COD concentrations, particularly in the stock dam, was investigated. The COD in the water of 3 treatments was measured in triplicate after different oxidation times. These results showed that the COD reading became constant in less than $1 \mathrm{~h}$ when the COD concentrations were below approx. 2 $000 \mathrm{mg} / \ell$ (Fig. 3). However, in the case of the high concentrations, e.g., in the stock dam, the COD readings only reached a plateau after approx. $90 \mathrm{~min}$. Based on these findings it was decided to standardise the oxidation time for all COD analyses to $2 \mathrm{~h}$.

As the project progressed, the abovementioned problems and possible causes for error were addressed and eliminated where possible. Due to this, the accuracy of the treatment application improved substantially in the subsequent seasons compared to 2009/10 (Fig. 2B, 2C \& 2D). Furthermore, after each irrigation, the target COD for the following irrigation was adjusted as follows:

$$
C_{A}=\left(C_{T} \times n\right)-\Sigma C_{P}
$$

where: $C_{A}$ is the adjusted COD concentration, $C_{T}$ is the target COD for a specific winery wastewater dilution treatment, $n$ is the number of the irrigation to be applied in a particular season

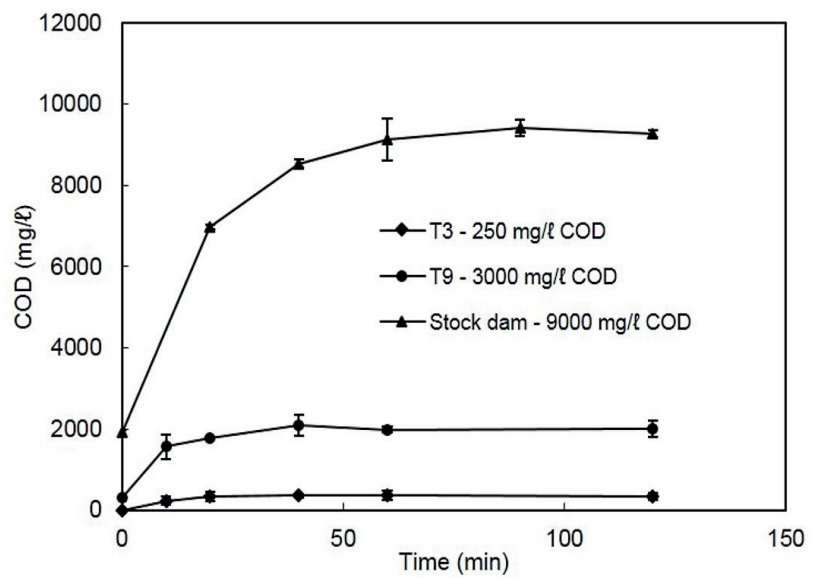

Figure 3

The effect of oxidation time on spectrophotometrically measured chemical oxygen demand (COD) in winery wastewater that was diluted to different $\mathrm{COD}$ levels. Vertical bars indicate standard deviation. and $C_{p}$ is the sum of the actual COD concentrations for the previous irrigations applied in the season. This continuous adjustment contributed to the fact that the mean actual COD was close to the target COD required for the different treatments for each of the 4 seasons (Fig. 2). This means that the actual total COD in the water applied was similar to the ideal situation, i.e., if the actual COD in the diluted winery wastewater had been exactly the same as the target for each irrigation.

Before the field work commenced, one of the major concerns was the efficiency of the mixing process in the tanks, i.e., during filling. On 12 April 2010, the variation in COD was measured as the irrigation progressed. The duration of the irrigations varied between $4.5 \mathrm{~h}$ and $5.5 \mathrm{~h}$. Hence, water samples were collected $1 \mathrm{~h}, 2.5 \mathrm{~h}$ and $5 \mathrm{~h}$ after the irrigations started. Water was sampled in triplicate only at the T4 and T9 tanks. Analyses of the water showed that the COD levels remained reasonably constant as the irrigation progressed, irrespective of the COD concentration (Fig. 4). Furthermore, it indicated that the COD concentrations in the diluted wastewater within the tanks were fairly homogeneous, and that effective mixing occurred while the tanks were being filled.

\section{CONCLUSIONS}

The relatively simple mix and distribution facility allowed dilution of large volumes of winery wastewater to a range of COD levels required for irrigating grapevines in a field trial. After initial practical problems and sources of error were eliminated, accuracy in terms of treatment application of the target COD concentrations was acceptable. Measuring COD concentrations while the irrigation water was being pumped from the tanks confirmed that the concentrations of diluted winery wastewater within the tanks were homogeneous, and that effective mixing had taken place while the tanks were being filled. By adjusting the COD level for the next irrigation according to the total COD applied via the preceding irrigations in a particular season, close agreement was obtained between the mean actual COD and the target values. When doing COD measurements, results will be more reliable if the oxidation time is standardised at $2 \mathrm{~h}$, irrespective of the level of COD in the water. The effect of irrigation with winery wastewater on the soil and grapevines will be reported in subsequent articles.

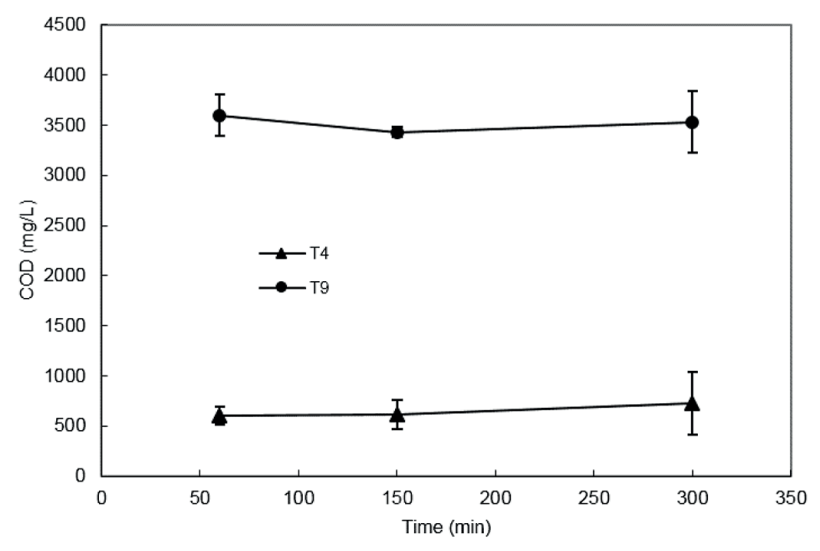

Figure 4

Temporal variation in chemical oxygen demand (COD) in diluted winery wastewater pumped from the mixing tanks for the irrigation of grapevines of 2 respective treatments, i.e., T4 \& T9. Vertical bars indicate standard deviation. 


\section{ACKNOWLEDGEMENTS}

We would like to acknowledge the following: the WRC for initiating and funding the project; Winetech, THRIP (TP1208066083) and ARC Infruitec-Nietvoorbij for co-funding; assistance of ARC Institute for Agricultural Engineering in designing the infrastructure; Goudini Wines for permission to work at their winery and in their vineyard; Messrs. Willie and Daniël Botha for managing the vineyard; and technical assistance of Soil and Water Science staff at ARC InfruitecNietvoorbij. Any opinions, findings and conclusions or recommendations expressed in any publication generated through THRIP-supported research, are those of the author(s) and therefore the NRF/THRIP will not accept any liability in that regard.

\section{REFERENCES}

ARIENZO M, QUALE WC, CHRISTEN E and JAYAWARDANE N (2009) Irrigating with winery wastewater? Developing soil stability thresholds and managing total cations. Aust. N.Z. Grapegrow. Winemak. October 2009 86-88.

BOOYSEN JH, STEENKAMP J and ARCHER E (1992) Names of vertical trellis systems (with abbreviations). Wynboer September 199215. CONRADIE A, SIGGE GO and CLOETE TE (2014) Influence of winemaking practices on the characteristics of winery wastewater and the water usage of wineries. S. Afr. J. Enol. Vitic. 35 10-18.

DWA (DEPARTMENT OF WATER AFFAIRS, SOUTH AFRICA)

(2013) Revision of general authorisations in terms of Section 39 of the National Water Act, 1998 (Act No. 36 of 1998), No. 665. Government Gazette No. 36820, 6 September 2013. Department of Water Affairs, Pretoria. 3-31.

LAURENSON S, BOLAN NS, SMITH E and MCCARTHY M (2012) Review: use of recycled wastewater for irrigating grapevines. Aust. J. Grape Wine Res. 18 1-10.

LE ROUX EG (1974) A climate classification for the South Western Cape viticultural areas (in Afrikaans). MSc thesis, Stellenbosch University, Stellenbosch, South Africa.

MULIDZI R, LAKER G, WOOLDRIDGE J and VAN SCHOOR L (2009a) Composition of effluents from wineries in the Western and Northern Cape provinces (Part 1): Seasonal variation and differences between wineries. Wynboer Technical Yearbook 2009/10 58-61.

MULIDZI R, LAKER G and WOOLDRIDGE J (2009b) Composition of effluents from wineries in the Western and Northern Cape provinces (Part 2): Impacts on soil and the environment. Wynboer Technical Yearbook 2009/10 62-68.

SOIL CLASSIFICATION WORKING GROUP (1991) Soil classification A taxonomic system for South Africa. Memoirs on Natural Resources of South Africa no. 15. Dept. Agric. Development, Pretoria. WINKLER AJ (1962) General Viticulture. University of California Press, Los Angeles. 